CASE REPORT

\title{
Fundoplication eliminates chronic cough due to non-acid reflux identified by impedance $\mathrm{pH}$ monitoring
}

\author{
I Mainie, R Tutuian, A Agrawal, A Hila, K B Highland, D B Adams, D O Castell
}

Thorax 2005;60:521-523. doi: 10.1136/thx.2005.040139

The symptoms of extra-oesophageal gastro-oesophageal reflux disease (GORD) (such as chronic cough and hoarseness) are traditionally more difficult to treat than typical GORD symptoms (heartburn and regurgitation). Patients with extra-oesophageal manifestations may require longer and higher doses of acid suppressive therapy. In patients not responding to acid suppressive therapy the physician faces a dilemma as to whether the symptoms are due to ongoing acid reflux, non-acid reflux, or not associated with reflux. We report the case of a 45 year old woman with a history of a chronic cough referred for fundoplication after documenting her symptoms were associated with non-acid reflux using multichannel intraluminal impedance and $\mathrm{pH}(\mathrm{MIl}-\mathrm{pH})$.

G astro-oesophageal reflux disease (GORD) is often included in the differential diagnosis for patients presenting with chronic cough, asthma, or voice changes. ${ }^{1}$ Identifying and treating patients in whom these symptoms are caused by GORD is challenging since patients with extra-oesophageal GORD symptoms usually require higher doses of acid suppressive medications for long periods of time. In patients with persistent symptoms during acid suppression, clarification of the relationship between the symptoms and acid or non-acid reflux can have a major impact on the patient's care. Patients with continuing acid reflux may benefit from increased doses of acid suppressive medication, ${ }^{2}$ patients with non-acid reflux may benefit from treatments aimed at augmenting the gastro-oesophageal barrier, while in patients in whom these symptoms are not associated with GOR episodes other aetiologies and therapeutic approaches should be sought. It is important to recognise that acid suppressive therapy is only changing the chemical composition of the gastro-oesophageal refluxate and pulmonary GORD symptoms may be caused by microaspiration of non-acid materials or by oesophagotracheobronchial reflexes caused by the presence of non-acid liquid in the distal oesophagus. ${ }^{3-5}$

Identifying non-acid reflux during conventional $\mathrm{pH}$ monitoring is difficult since the criterion for identifying acid GOR episodes requires the $\mathrm{pH}$ to decrease to below 4.0. Combined multichannel intraluminal impedance and $\mathrm{pH}(\mathrm{MII}-\mathrm{pH})$ has recently been proposed as a new technique which has the ability to identify all types of reflux and to evaluate symptom associations with both non-acid and acid reflux.

\section{CASE REPORT}

A 45 year old non-smoking woman was referred by the pulmonary department to the oesophageal clinic with a 2 year history of a frequent non-productive cough. Coughing spells occurred only during the daytime without any predictable inciting events. The physical examination was unremarkable. Treatment with lansoprazole $30 \mathrm{mg}$ daily and

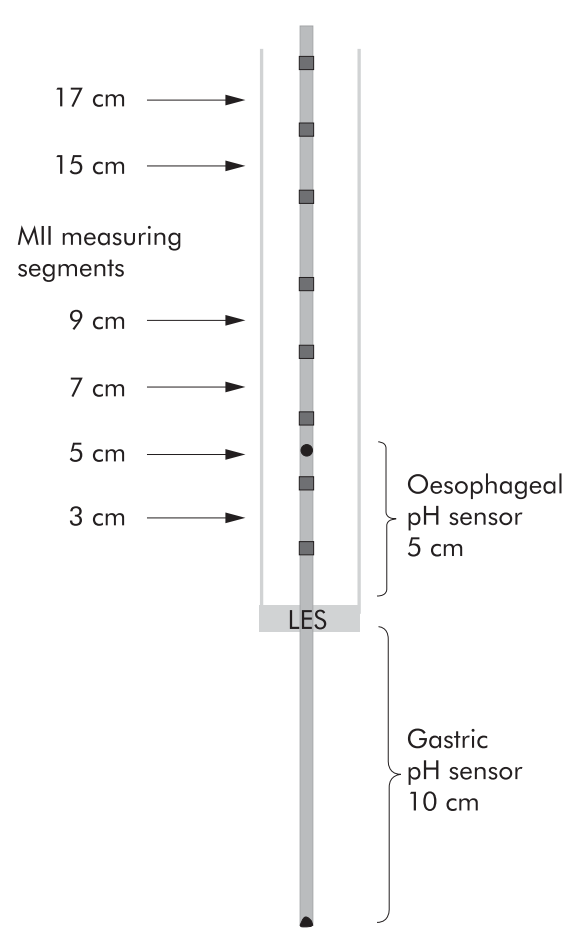

Figure 1 Multichannel intraluminal impedance-pH catheter (diameter $2.1 \mathrm{~mm}$ ) with impedance electrodes (4 mm in length) set in pairs at $2 \mathrm{~cm}$ intervals. This allows for six impedance rings and one $\mathrm{pH}$ electrode in the oesophagus and a second $\mathrm{pH}$ electrode in the stomach. The $\mathrm{pH}$ sensor is placed $5 \mathrm{~cm}$ above the lower oesophageal sphincter (LES) and impedance values at six different sites at 3, 5, 7, 9, 15 and $17 \mathrm{~cm}$ above the LES and gastric $\mathrm{pH}$ at $10 \mathrm{~cm}$ below the LES.

famotidine $20 \mathrm{mg}$ at bedtime in addition to instructions for lifestyle modifications (such as sleeping with the head of the bed elevated, avoiding late meals, avoiding the recumbent position for 3 hours after meals, etc) had resulted in a decrease in her symptoms of acid taste and regurgitation but there was no improvement in her cough. A 24 hour pH study on this treatment showed abnormal distal oesophageal acid exposure but negative symptom association with cough. At this point other causes and treatments for her cough were pursued. Pulmonary function tests, chest radiographs, a CT scan of the chest, and cardiac stress test were reported as normal. The patient was empirically treated with various inhalers, cough suppressants, and nebulised lidocaine, but without improvement. Ambulatory 24 hour MII-pH study on medication (lansoprazole $30 \mathrm{mg}$ qd and famotidine $20 \mathrm{mg}$

Abbreviations: $\mathrm{MIl}-\mathrm{pH}$, multichannel intraluminal impedance and $\mathrm{pH}$; LES, lower oesophageal sphincter; GOR, gastro-oesophageal reflux; GORD, gastro-oesophageal reflux disease; LNF, laparoscopic Nissen fundoplication 
qhs) revealed inadequate acid control with abnormal distal oesophageal acid exposure (upright 9.3\%; normal $<6.3 \%$, recumbent $6.3 \%$; normal $<1.2 \%$ ) and a positive symptom correlation for cough (1/1) with non-acid reflux.

A more aggressive acid suppressive therapy was initiated (esomeprazole $40 \mathrm{mg}$ bid and famotidine $60 \mathrm{mg}$ qhs) with the thought that better acid control may be required to eliminate her symptoms. During a follow up visit 2 months later the patient denied any typical GORD symptoms but continued to have persistent cough. A repeat MII-pH study on esomeprazole $40 \mathrm{mg}$ bid and famotidine $60 \mathrm{mg}$ qhs revealed normal oesophageal acid exposure on treatment (distal oesophageal acid exposure over 24 hours $=0 \%$ ) with a positive symptom index (3/6) for cough associated with non-acid reflux.

At this point the patient was diagnosed with non-acid reflux induced cough and, since the side effects of currently available promotility agents often outweigh their benefits, she was referred to the surgical service to be evaluated for antireflux surgery. She underwent a laparoscopic Nissen fundoplication (LNF) and reported complete resolution of her cough during the 2 month postoperative follow up visit. One year after the operation the patient reported continued resolution of her cough despite not taking any acid suppressing medications.

\section{DISCUSSION}

GORD has been implicated in the past as one of the most common aetiologies for chronic cough, but it is often difficult to diagnose and treat. Three mechanisms by which reflux may induce cough have been proposed: oesophagotracheobronchial cough reflex, macroaspiration, and microaspiration. Irwin et al studied nine patients before and after treatment for GORD and found an association between cough and GORD, thus concluding that acid stimulates distal oesophageal mucosal receptors resulting in a cough reflex. ${ }^{3}$ Ing et al showed that GORD occurred simultaneously in $78 \%$ of cough episodes and within 5 minutes in another $12 \%$ of episodes. ${ }^{4}$ The vagally mediated cough reflex was supported by a study using distal oesophageal acid perfusion. There was a significant increase in cough frequency in the acid group compared with the saline group. When the afferent pathway was blocked by the instillation of lidocaine, there was a
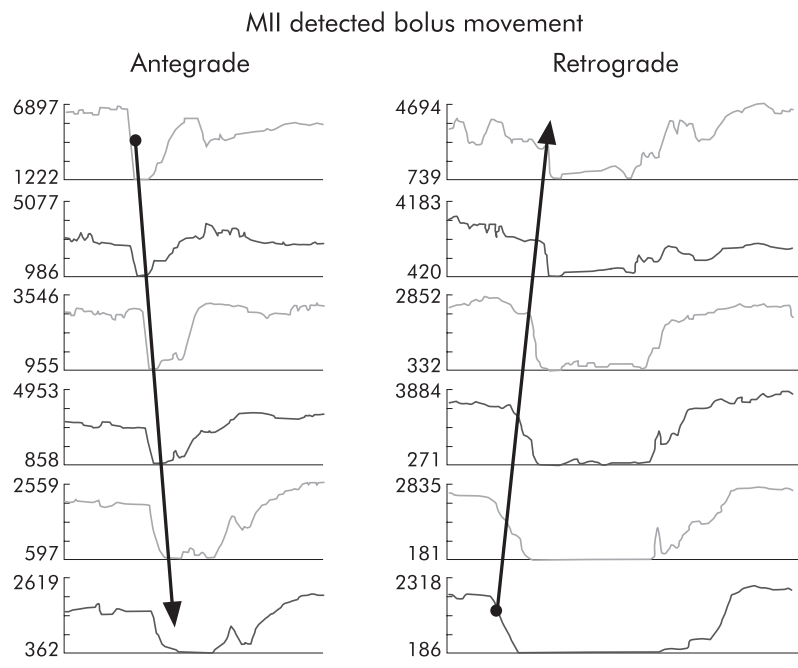

Figure 2 Differences in impedance changes during swallowing and reflux. Changes in impedance progressing from proximal to distal indicate antegrade bolus movement as seen during swallowing while changes in impedance progressing distally to proximally indicate retrograde bolus movement as seen during reflux. decrease in the frequency of acid infused coughs. Blocking the efferent pathway with nebulised ipatropium bromide also inhibited cough, an effect not seen with oesophageal ipatropium. ${ }^{5}$

Microaspiration and macroaspiration from proximal oesophageal reflux are the other proposed mechanisms for GORD induced cough. This can result from a small volume of refluxate causing laryngeal inflammation sometimes associated with bronchial inflammation. Aspiration initiates a cough by irritating the cough receptors in the lower airway or by triggering a vagally mediated reflex from irritation of the sensory nerves in the airway epithelium (cough receptors). ${ }^{3}$ Extra-oesophageal symptoms have been successfully treated by proton pump inhibitors in the past, despite negative studies for acid reflux. ${ }^{6}$ Extra-oesophageal symptoms usually require longer treatment duration and higher doses of proton pump inhibitors and do not respond as well as typical GORD symptoms to acid suppression.

Recent studies have shown successful surgical treatment of extra-oesophageal symptoms. Five year follow up studies of patients with GORD related cough following LNF have shown an improvement in up to $71 \%$ of patients. ${ }^{7}$ Irwin et $a l^{8}$ studied eight consecutive patients with a history of chronic cough not improved on intensive acid suppression therapy. In three of these patients gastrointestinal symptoms improved on medication whereas cough remained unchanged. This finding is similar to our patient (improvement in heartburn on acid suppression therapy but persistent cough), underscoring the fact that improvement of typical GORD symptoms does not necessarily mean the elimination of gastro-oesophageal reflux responsible for extra-oesophageal manifestations. The patients were evaluated by 24 hour oesophageal $\mathrm{pH}$ monitoring while on treatment and were reported to have complete or nearly complete acid suppression. Each patient had a bronchoscopic examination and gastrointestinal (GI) investigations (barium oesophagography, gastric emptying, upper GI endoscopy and oesophageal manometry) to rule out other possible aetiologies for cough. After GI evaluations to identify any abnormality before antireflux surgery, the patients underwent LNF. They were followed for 1 year to compare preoperative and postoperative cough severity (using a visual analogue scale) and health related dysfunction due to cough (using adverse cough outcome survey questionnaires) and then by telephone for 2.5-4 years. The results showed complete resolution or marked improvement in cough in all patients. The study concluded the cause of the cough was non-acid reflux. ${ }^{8}$ Antireflux surgery has shown an improvement in patients with a chronic cough despite treatment with proton pump inhibitors, but emphasis has been placed on the importance of appropriate patient selection.

Multichannel intraluminal impedance (MII) is a new technique which allows the detection of GOR independent of $\mathrm{pH}$ by recording electrical resistance within the oesophagus. ${ }^{9}$ Impedance detects the presence of liquid boluses within the oesophagus based on changes in electrical conductivity of the intraluminal content. Liquid boluses conduct better than the empty oesophagus leading to a rapid decline in intraluminal impedance when the bolus is entering the impedance measuring segment (the impedance will return to baseline once the bolus exits the impedance measuring segment). Multiple impedance measuring segments mounted on the same catheter (fig 1) allow determination of the direction of bolus movement. Impedance changes progressing proximal to distal are indicative of liquid swallows while impedance changes progressing distal to proximal indicate reflux episodes. Figure 2 shows examples of a swallow and a reflux event detected by impedance. Air present in the oesophagus leads to a rise in impedance since its conductivity 


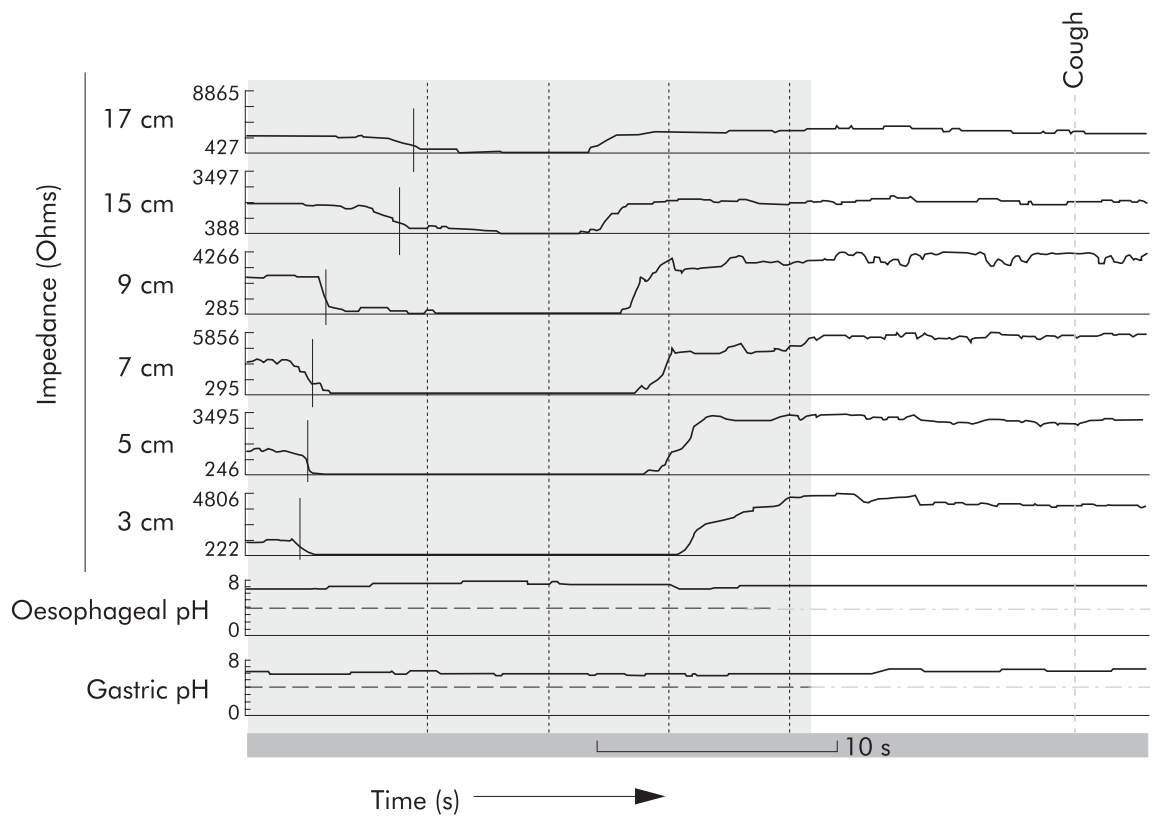

Figure 3 Tracing from the multichannel intraluminal impedance-pH study. The six impedance measuring segments and one $\mathrm{pH}$ site are shown on the $y$ axis. The left tracing shows a fall in impedance (measured in ohms) beginning distally as liquid travels retrograde up the oesophagus. Both the gastric and oesophageal $\mathrm{pH}$ remain above 4 during the reflux episode. The vertical lines correspond to the retrograde reflux event. The dotted line identifies the $\mathrm{pH} 4$ level. The patient's symptom occurred within seconds after this reflux episode. The tracing on the right shows a fall in the impedance (measured in ohms) beginning proximally as liquid travels down the oesophagus.

is lower than that of the empty oesophagus. MII has the ability to identify liquid, gas and mixed (liquid-gas or gasliquid) refluxes. Combined with $\mathrm{pH}(\mathrm{MII}-\mathrm{pH})$, impedance allows characterisation of the chemical conent of the refluxate. Impedance detected reflux episodes during which the $\mathrm{pH}$ drops to below 4.0 are considered acid reflux episodes while episodes during which the $\mathrm{pH}$ stays above 4.0 are traditionally considered non-acid (fig 3 ). By its ability to identify all types of reflux episodes, combined MII-pH is currently the ideal technique to evaluate patients with residual symptoms on acid suppressive therapy. ${ }^{9}$

In summary, even though successful surgical treatment of patients with GORD induced cough has been previously reported, the current case is the first one objectively to document the association of pulmonary symptoms with nonacid reflux. In addition, it is the first case to demonstrate the effect of combined MII-pH on clinical decision making. In our institution we are in the process of collecting data on patients who have had a positive association between symptoms and reflux during an MII-pH study who have been treated with a fundoplication. Further outcome studies are warranted to evaluate the role of combined MII-pH on clinical decisions regarding patients with symptoms potentially due to non-acid reflux.

\section{Authors' affiliations}

I Mainie, R Tutuian, A Agrawal, A Hila, D O Castell, Division of Gastroenterology and Hepatology, Medical University of South Carolina, Charleston, USA

K B Highland, Division of Pulmonary, Critical Care and Allergy, Medical University of South Carolina, Charleston, USA
D B Adams, Department of Surgery, Medical University of South Carolina, Charleston, USA

Correspondence to: Dr I Mainie, Gastroenterology Fellow, Medical University South Carolina, 96 Jonathan Lucas Street, 210 Clinical Science Building, P O Box 250327 Charleston, SC 29425, USA; mainie@musc.edu

Received 5 January 2005

Accepted 19 March 2005

\section{REFERENCES}

1 Barish CF, Wu WC, Castell DO. Respiratory complications of gastrooesophageal reflux. Arch Intern Med 1985;145:1882-8.

2 Castell DO, Kahrilas PJ, Richter JE, et al. Esomeprazole $(40 \mathrm{mg}$ ) compared with lansoprazole (30 $\mathrm{mg}$ ) in the treatment of erosive oesophagitis. Am J Gastroenterol 2002;97:575-83.

3 Irwin RS, Madison JM, Fraire AE. The cough reflex and its relation to gastrooesophageal reflux. Am J Med 2000;108(Suppl 4a):73-8S.

4 Ing AJ, Ngu MC, Breslin AB. Chronic persistent cough and gastrooesophageal reflux. Thorax 1991;46:479-83.

5 Ing AJ, Ngu MC, Breslin AB. Pathogenesis of chronic persistent cough associated with gastroesophageal reflux. Am J Respir Crit Care Med 1994; 149:160-7

6 Ours TM, Kavuru MS, Schilz RJ, et al. A prospective evaluation of esophageal testing and a double-blind, randomized study of omeprazole in a diagnostic and therapeutic algorithm for chronic cough. Am J Gastroenterol 1999;94:3131-8.

7 Allen CJ, Anvari M. Does laparoscopic fundoplication provide long-term control of gastro-oesophageal reflux related cough? Surg Endosc 2004; 18:633-7.

8 Irwin RS, Zawacki JK, Wilson M, et al. Chronic cough due to gastrooesophageal reflux disease: failure to resolve despite total/near-total elimination of esophageal acid. Chest 2002;121:1132-40.

9 Tutuian R, Vela MF, Shay SS, et al. Multichannel intraluminal impedance in esophageal function testing and gastro-oesophageal reflux monitoring. J Clin Gastroenterol 2003;37:206-15. 